\title{
Importance of district of residence and known primary site for bowel cancer survival: analysis of data from Wessex Cancer Registry
}

\author{
R M Pickering, I R Chadwell, L Mountney
}

\begin{abstract}
Study objective-The aim was to compare survival with colon and rectal cancer across the 10 districts of Wessex taking into account the age and sex of the individual.

Design-The study was based on registrations on the Wessex Cancer Registry between 1979 and 1984 with colon and rectal cancer. Survival up to 31 December 1986 was examined using a Cox regression model; individuals surviving to the end of the follow up period were treated as censored in the analysis. Survival was examined in the first fortnight, the first month, and the first six months after registration separately.

Participants-The data comprised 6239 residents of the Wessex Region who had been diagnosed with colon cancer and 3203 residents diagnosed with rectal cancer. For 140 cases survival data or age were missing and these cases were excluded.
\end{abstract}

Measurements and main resultsResults are presented in the format of a league table giving the order of districts from lowest to highest survival rates. No significant differences in survival are found between districts in relation to rectal cancer. We find that one or two districts have consistently high or low survival rates with colon cancer in various periods of follow up, but cannot differentiate between the districts in the centre of the list. Site unspecified is considered as an explanatory variable; it is more predictive than district, and it approaches the importance of age in explaining survival with colon cancer.

Conclusions-There are significant differences in survival with colon cancer between districts; however data on stage at registration are not available and we are unable to say whether the differences in survival are due to differences in stage at diagnosis or differences in survival with similar stage at diagnosis. We found that cases where the site of the cancer within the colon was not recorded on the register have significantly lower survival, and we suggest that site unspecified may be related to stage at diagnosis.

The background to this analysis lies in the desire to compare survival rates for bowel cancer between the 10 health districts of Wessex. Survival from rectal cancer in particular may be influenced by the type of treatment, and hence a comparison of district survival could suggest districts where care might potentially be improved. Similar analyses are routinely performed in many areas for administrative or planning purposes and in the production of performance indicators. The results of such analyses are commonly presented in a league table, listing districts or hospitals in order from lowest to highest (and often by implication, from best to worst) with respect to the outcome in question. Problems can arise in the interpretation of such tables. In this paper we proceed with a league table analysis of survival from colorectal cancer using data from the Wessex Cancer Registry. We examine the importance of district, primary site, and age in predicting survival, noting problems in the analysis and interpretation when they arise.

Survival after treatment for colorectal cancer varies greatly with stage of the disease, age/sex adjusted five year survival being close to $100 \%$ for patients with Duke's type A disease, whereas patients with Duke's type $C$ have a five year adjusted survival rate of less than $30 \%$, and those with Duke's type D have a five year adjusted survival rate of about $5 \% .{ }^{1}$ The delay between onset of symptoms and treatment has been shown to be on average of the order of 30-40 weeks. ${ }^{2}$ Delay is formed from three parts: that due to patients delaying seeing their family doctors, that due to the family doctor delaying referring to hospital, and finally delay in achieving hospital appointments. The stage of the cancer at notification is not available from the Wessex Cancer Registry, neither is it possible to verify that the case was notified at diagnosis. District differences in registered survival may thus reflect differences in delay before treatment, they may reflect differences in survival following treatment, or they may reflect differences in the notification procedure.

\section{Methods}

DATA

Since 1973 cancers diagnosed in residents of Wessex have been notified to the Wessex Cancer Registry. A case is notified to the registry whenever a Wessex resident or a patient treated in Wessex is diagnosed with cancer. Each case is flagged on the National Health Service Central Register, and when death from any cause occurs the registry is informed. Information on cause of death is not sufficiently reliable to differentiate between death due to cancer and death from other causes; for this reason we analyse all cause survival and refer to survival with cancer rather than death from cancer. Since no other complete list of cancers exists the coverage of the registry cannot routinely be examined, but ad hoc comparisons ${ }^{3} 4$ suggest that the completeness of registration has

Medical Statistics and
Computing,
University of
Southampton, South
Academic Block,
Southampton General
Hospital,
Southampton SO9
4XY, United Kingdom
R M Pickering
I R Chadwell
Wessex Cancer
Intelligence Unit
L Mountney
Correspondence to:
Dr Pickering
Accepted for publication
June 1991


increased since its formation, attaining by 1986 a coverage of $92 \%$ for tumours other than skin cancer, where rates are lower. The following information was obtained from the Wessex Cancer Registry for 9442 residents of the Wessex Region, all of whom had been diagnosed as having cancer of the colon or rectum during 1979-1984: date of birth, anniversary date (closest date available to date of diagnosis), date of death, ICD four digit site code, Wessex health district, and sex.

The registry records the International classification of diseases 9 th revision (ICD) code for the tumour. The ICD code contains four digits; the first three digits indicate whether the tumour was found in the colon (153) or rectum (154). The fourth digit gives the specific site of the cancer within the colon or rectum. The frequencies of reported ICD codes are given in table $I$, and show 6239 cases of bowel cancer and 3203 cases of rectal cancer. Survival is compared between the rectum, the left colon (descending and sigmoid), the central colon (transverse, and the hepatic and splenic flexures), and the right colon (ascending, and the caecum and appendix). A large proportion of cases $(40 \%)$ have site in colon unspecified and a variable representing colon site specified or not is considered in the analysis. A few cases (199 between 1979 and 1984) have ICD code 159.0 representing site unspecified, more generally, within the intestine.

The anniversary date should ideally be the date of diagnosis, but could be the date on which the patient was first discharged from hospital or seen as an outpatient. If the patient did not enter the hospital system at all then the anniversary date could be the same as the date of death if either the date of diagnosis was missed or the malignancy was discovered at necropsy. Information about deaths is considered complete up till the end of 1986. Survival time is the time between the anniversary date and death. Age at diagnosis is categorised in age bands: <60, 60-64, 65-69, $70-74,75-79,80-84, \geqslant 85$ years. For 140 cases survival time or age were missing because either the day or month of one of the dates was absent; in all cases the year was present. Cases with missing age or survival are excluded. Were more ages missing it would be worth assigning them to the appropriate age group where possible. All cases have sex recorded. The health district on the register is the district of usual residence. The 10 districts are been labelled $\mathrm{A}$ to J. After excluding

Table I Frequencies of recorded ICD code

\begin{tabular}{llrr}
\hline Site of tumour & ICD code & Frequency & Percentage \\
\hline \multicolumn{1}{c}{ Colon } & & & \\
Hepatic flexure & 153.0 & 98 & $1.6^{\circ} \%$ \\
Transverse colon & 153.1 & 329 & $5.3^{\circ}{ }^{\circ}$ \\
Descending colon & 153.2 & 217 & $3.5^{\circ}$ \\
Sigmoid colon & 153.3 & 1470 & $23.6^{\circ}{ }^{\circ}$ \\
Caecum & 153.4 & 1083 & $17.4^{\circ}{ }^{\circ}$ \\
Appendix & 153.5 & 35 & $0.1^{\circ}$ \\
Ascending colon & 153.6 & 342 & $5.5^{\circ}{ }^{\circ}$ \\
Splenic flexure & 153.7 & 153 & $2.5^{\circ}{ }^{\circ}$ \\
Other & 153.8 & 10 & $0.0^{\circ}$ \\
Colon unspecified & 153.9 & 2502 & $40.1^{\circ}{ }^{\circ}$ \\
Total & & 6239 & $100.0^{\circ}{ }^{\circ}$ \\
& & & \\
Rectosigmoid junction & 154.0 & 338 & $10.6^{\circ}{ }^{\circ}$ \\
Rectum & 154.1 & 2742 & $85.6^{\circ}{ }^{\circ}$ \\
Anal canal & 154.2 & 38 & $1.2^{\circ}$ \\
Anus unspecified & 154.3 & 70 & $2.2^{\circ}$ \\
Other & 154.8 & 15 & $0.0^{\circ}{ }^{\circ}$ \\
Total & & 3203 & $100.0^{\circ}{ }^{\circ}$ \\
\hline
\end{tabular}

cases with missing survival or age, 6150 cases with colon cancer and 3152 cases with rectal cancer remain for survival analysis.

\section{STATISTICAL METHODS}

No date of death was recorded for 2769 cases and they are assumed alive on 31 December 1986, and treated as censored at this date. A small number of cases (232) had date of death recorded in 1987, 1988 , and/or 1989, and are also censored at the end of 1986. Specific periods of follow up are analysed by treating as censored those cases alive at the end of the period, and excluding deaths before the start of the period. The Cox proportional hazards survival model $^{5}$ is estimated using the BMDP statistical package. ${ }^{6}$ The significance of terms in the Cox model is evaluated using score tests, which, for district terms, are compared to a $\chi^{2}$ distribution on 9 degrees of freedom. Confidence intervals at the $95 \%$ level are computed using approximate standard errors. The proportionality assumption underlying the model is examined by plotting the log of observed monthly hazards, that is the death rate among those alive at the start of each month. If the model is appropriate, district observed log hazards should be a constant distance apart at each month, though some degree of random variability from this pattern would be expected particularly for the smaller districts. Periods of time other than months can be chosen, and are indicated on the plots. The observed log hazard for a period is plotted at its midpoint. Five year survival plots are based on Kaplan-Meier estimates.

Where the score test shows a significant difference between districts we wish to see where the difference lies. There are 45 comparisons to draw between the 10 districts, and ideally a multiple comparison procedure would be used to maintain an overall significance level. There is considerable variation in the number of registered cases between districts, and a smaller difference in actual risk between larger districts could be judged significant, while a larger actual difference between smaller districts might not. Thus it would be difficult to summarise the results of such a procedure. For each analysis we present here only the order in which the districts lie from low to high hazard, while an idea of the spread of hazards can be gained from the ratio between the greatest and least district hazards. League tables usually include a rate for each district, but this is not easily obtained from a controlled analysis where districts are compared to a baseline.

\section{Results}

Age was a highly significant risk factor, with hazards increasing gradually up to age group 75-79 years; the hazards for the 80-84 year age group showed a greater increase, and among those aged over 85 years hazards were very high. This pattern was expected since we are examining all cause survival. In most analyses sex did not have a significant impact on survival, though it has been included as a controlling factor.

The plots of district observed log hazards for the whole period of follow up showed a confused pattern with the lines constantly crossing, 
indicating that relative hazards between districts change depending on the period of follow up. Figure 1 shows observed log hazard rates with colon cancer for each district during the first month. Even within this short period the district lines cross, but it is possible to distinguish districts which tend to stay at or near the extremes (districts A, B, I, and J). Survival models controlled for age and sex are estimated in specific periods of follow up to examine variation over time in patterns of relative hazard. Firstly, the model is fitted to the whole period of follow up; then the first six months and the remaining

Figure 1 Observed district log hazard rates during the first month. Log hazards are calculated for days 1-2, 3-4, 5-6 and thereafter in four day intervals. The log hazards for day 0 are also plotted, at $x=-1$ for clarity.

Table II $\chi^{2}$ Tests for district effects in survival (controlled for age and sex), $9 d f$

Table III Orders of districts with respect to hazard and ratios of greatest to least hazard controlled for age and sex, colon cancer



\begin{tabular}{|c|c|c|c|c|}
\hline & \multicolumn{4}{|l|}{ Site } \\
\hline & Colon & $p$ & Rectum & $p$ \\
\hline $\begin{array}{l}\text { Whole period } \\
\text { Months >6 } \\
\text { Months 1-6 } \\
\text { Months 2-6 } \\
\text { Month 1 } \\
\text { Days 15-30 } \\
\text { Days 0-14 }\end{array}$ & \begin{tabular}{r|}
30.98 \\
15.17 \\
16.22 \\
6.07 \\
25.76 \\
23.26 \\
30.03
\end{tabular} & $\begin{array}{l}0.0003 \\
0.0865 \\
0.0624 \\
0.7324 \\
0.0022 \\
0.0056 \\
0.0004\end{array}$ & $\begin{aligned} 7.33 \\
17.57 \\
12.31 \\
7.01 \\
11.83 \\
7.08 \\
11.19\end{aligned}$ & $\begin{array}{l}0.6031 \\
0.0405 \\
0.1965 \\
0.6362 \\
0.2231 \\
0.6287 \\
0.2628\end{array}$ \\
\hline $\begin{array}{l}\text { Anc } \\
\text { Whole period } \\
\text { Months 1-6 } \\
\text { Month 1 } \\
\text { Days 1-14 }\end{array}$ & $\begin{array}{c}\text { rcluding } \\
26.26 \\
12.38 \\
24.39 \\
22.20\end{array}$ & $\begin{array}{c}\text { ases with } \\
0.0019 \\
0.1928 \\
0.0037 \\
0.0083\end{array}$ & $\begin{array}{c}\text { O survival } \\
6.10 \\
9.55 \\
9.60 \\
5.98\end{array}$ & $\begin{array}{l}0.7294 \\
0.3881 \\
0.3837 \\
0.7419\end{array}$ \\
\hline
\end{tabular}
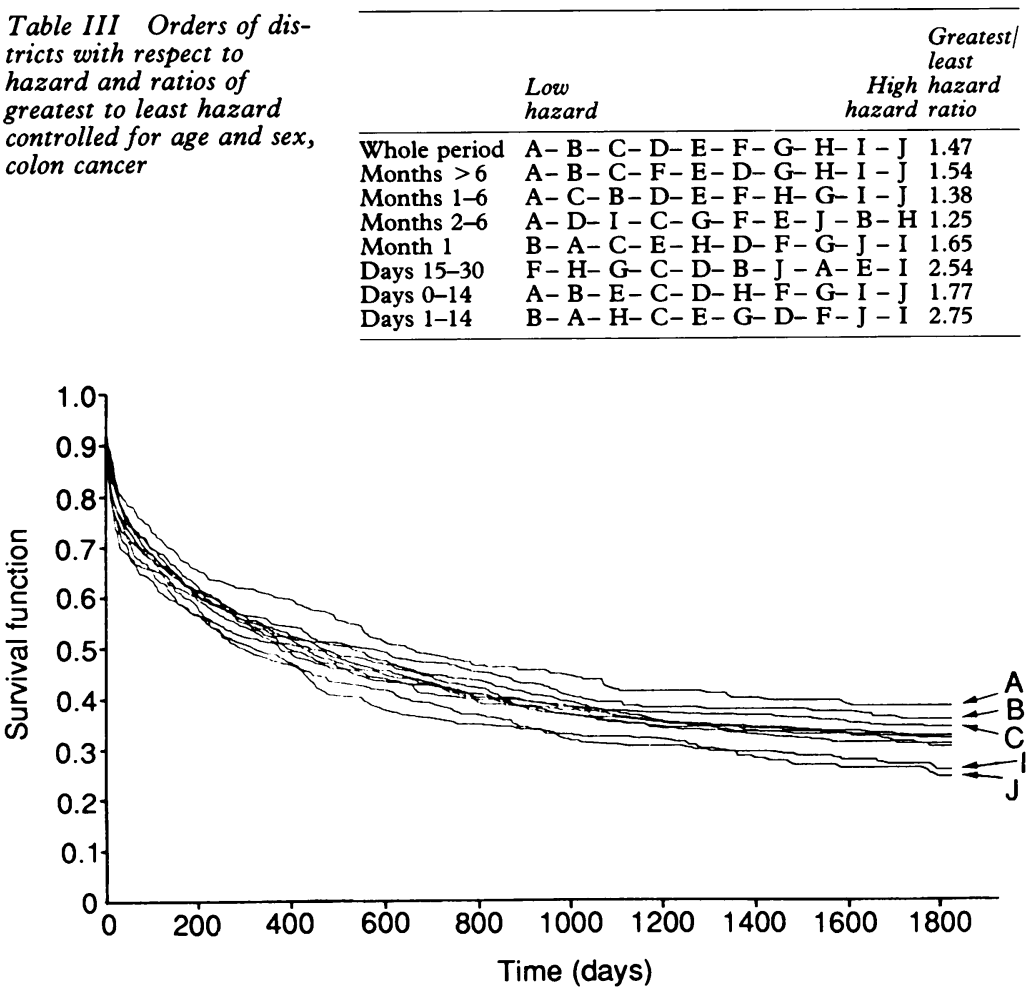

Figure 2 District five year survival curves months are examined separately. Within the first six months two periods are examined, the first month and months $2-6$. Finally, the first 14 days and the remaining days of the first month are examined separately. Tests for district difference in survival with colon and rectal cancer are given in table II for each period to follow up. There are significant differences in survival from colon cancer between districts in the whole period, in the first six months, in the first month, and also in the two halves of the first month. Turning to rectal cancer, during months greater than six the district effect reaches marginal significance, but with the number of tests performed this could be due to chance. Survival from rectal cancer is not examined further.

In table III the orders of the districts with respect to their hazard to survival with colon cancer are presented, together with the ratio of greatest to least hazard. Districts with lower hazard are placed to the left of the figure and districts with higher hazard to the right. Districts $\mathrm{J}$ and $\mathrm{I}$ appear at high hazard in most periods of follow up, while districts $A$ and, to a lesser extent, $B$ usually have low hazard. The biggest changes in order occur between the two halves of the first month and both periods show high significance in table II $(p=0.0004$ for days $0-14, p=0.0056$ for days 15-30). District $A$, which appears at the extreme of low hazard in days $0-14$, moves to third highest in the analysis of days 15-30. The district order from the first month resembles that from days 0-14 rather than that from days 15-30. In months 2-6, where the district effect was non-significant, there are again considerable changes to the order. Even though the analyses of months $1-6$, and months $>6$, do not show significance, the district orders, at least in the extremes, are similar to those from the first month and from days $0-14$, as is the order from the analysis of the whole period. To summarise, districts A, B, I, and $\mathrm{J}$ often appear at the extremes of table III as they did in fig 1 . In fig 2 survival rates are plotted during the first five years. In the centre of the plot there is much overlap and individual lines cannot be discerned. Districts A, B, I, and J can be seen to have extreme survival rates throughout most of the period.

Among the individuals with colon cancer, 510 $(8.3 \%)$ had zero survival, that is, their registered anniversary date and date of death are the same. The order of districts with respect to their rates of zero survival from lowest to highest is given in table IV, the range across districts being $4.6-11.1 \%$. The districts with highest rates of zero survival are also those with high hazard to survival, but there is little correspondence between districts with low rates or hazards respectively. The analyses of the whole period, the first six months, the first month, and days 0-14 were repeated without the zero survival cases. Significance levels from these analyses (table II) are lower than levels obtained when cases with zero survival were included. District orders from these analyses showed one or two swaps of adjacent districts at the extremes, and districts even three or four places apart at the centre. The biggest differences occur, not surprisingly, when cases with zero survival are removed from the analysis of days 0-14 (table III, final 
row). The presence of large numbers of cases with zero survival in a district may indicate poor survival or alternatively underascertainment. In the latter case a district survival rate would be biased downwards were zero survival cases included. If they are excluded, a bias in the opposite direction would result where they genuinely represent short survival. The period specific analyses of colon cancer were repeated excluding districts $G$ and $J$, the districts with highest rates of zero survival. The resultant district orders were identical to those shown in table III, omitting $G$ and $J$, while significance levels were generally lower than those shown in table II.

Approximately $40 \%$ of cases with colon cancer had the site of the lesion unspecified. In table $\mathrm{V}$ relative hazards for left, central, and right colon, and unspecified site within the colon are compared to the rectum, and their $95 \%$ confidence intervals are given. The most obvious feature is the high hazard experienced by those with unspecified colon site. The relative hazards do not show a gradient of increasing hazard within the colon from right to left and this may be because high risk cases have no site recorded. The district rates of unspecified site varied considerably, between $25 \%$ and $60 \%$, and the order of districts with respect to their risk of having an unspecified site (table IV) is not similar to that for survival with colon cancer. Cases without a site specified in the colon are more likely to have zero survival $(11.7 \%)$ than cases with a site recorded $(6.0 \%)$, though there is little similarity between the district orders for unspecified site and zero survival, except in that district $E$ has the lowest of both rates. The percentage of cases without a specified site did not vary greatly with year of registration, sex, or age (though the percentage was greater among those with missing age). Because so many cases have site unspecified, and the rate varies greatly with district, we proceed to examine the role of unspecified site in predicting survival.

In table VI $\chi^{2}$ test values are given for district, the site specification variable, and age in explaining survival from colon cancer. The site specification variable accounts for a much greater improvement in fit than the district variable, and taking into account the degrees of freedom, site specification approaches the importance of age in improving fit (table VI). In fig 3 the observed log hazard plot for the first five years shows that the proportionality assumption for site specification is not unreasonable during the first year and a half, but the lines cross after this period. In table VII the district orders controlled for site

Table IV Order of district with respect to rates of unspecified site and zero survival, colon cancer

\begin{tabular}{|c|c|c|}
\hline & $\begin{array}{l}\text { Low } \\
\text { rate }\end{array}$ & $\begin{array}{c}\text { High } \\
\text { rate }\end{array}$ \\
\hline $\begin{array}{l}\text { Zero survival } \\
\text { Site unspecified }\end{array}$ & & $\begin{array}{l}\mathrm{J}-\mathrm{G} \\
\mathrm{B}-\mathrm{H} \\
\end{array}$ \\
\hline
\end{tabular}

Table $V$ Relative hazards of sites in colon and rectum controlled for age and sex, analysis of the whole period ( $95 \%$ confidence intervals in brackets)

\begin{tabular}{lllll}
\hline \multirow{5}{*}{ Rectum } & Site & \multicolumn{4}{l}{} \\
\cline { 2 - 5 } & Left colon & Centre colon & Right colon & Unspecified colon \\
\hline 1.000 & 1.028 & 1.108 & 0.900 & 1.3205 \\
& $(0.953,1.110)$ & $(0.994,1.234)$ & $(0.835,0.971)$ & $(1.240,1.407)$ \\
\hline
\end{tabular}

specification are given and are similar to those in table III, uncontrolled for site specification. Thus in spite of the demonstrated association between survival and site specified and the large variation in rates of unspecified site between districts, controlling for site specified or not made little difference to the district orders with respect to survival.

\section{Discussion}

Although differences in survival with colon cancer between districts have been detected, they were primarily accounted for by one or two districts experiencing consistently high or low hazards throughout the period of follow up. It was not possible to differentiate within the main body of districts. District differences were easiest to detect very early on in follow up, partly because the death rates were highest in these periods, and hence more statistical power was available, and partly because greater extremes in risk were found. Analyses of periods excluding the first 14 days, showed more changes in the order in which districts were placed compared to analyses that

Table VI $\chi^{2}$ Tests for district effects and specified site or not, colon cancer

\begin{tabular}{|c|c|c|c|c|c|}
\hline & $\begin{array}{l}\text { District }^{\mathrm{a}} \\
\text { effect } \\
(\mathbf{9} \mathrm{df})\end{array}$ & $t^{\mathrm{a}}$ & $\begin{array}{l}\text { Specified } \\
\text { or not } \\
(1 \text { df })\end{array}$ & to & $\begin{array}{l}A g e^{\mathrm{c}} \\
(6 d f)\end{array}$ \\
\hline Whole period & 39.37 & $<0.0001$ & 95.65 & $<0.0001$ & 603.43 \\
\hline Months $>6$ & 15.94 & 0.06 & 3.32 & 0.0 & 77.51 \\
\hline Months $1-6$ & 24.24 & 0.0039 & 121.92 & $<0.0001$ & 599.51 \\
\hline Months 2-6 & 9.22 & 0.4174 & 35.46 & $<0.0001$ & 92.40 \\
\hline Month 1 & 29.73 & 0.0005 & 83.99 & $<0.0001$ & 550.64 \\
\hline Days $15-30$ & & 0.0027 & & 0.0001 & 113.45 \\
\hline Days $0-14$ & 32.46 & 0.0002 & 68.78 & $<0.0001$ & 443.61 \\
\hline
\end{tabular}

a Controlled for age, sex, specified or not

b Controlled for age, sex, district

c Controlled for sex, district

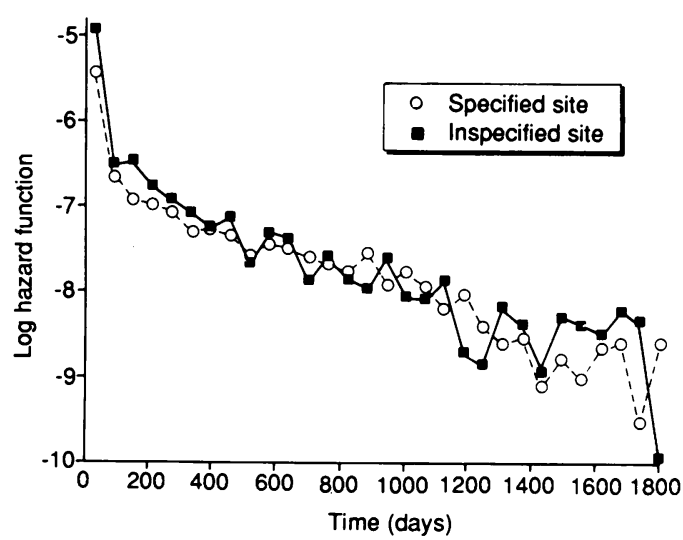

Figure 3 Observed log hazard rates for site in colon specified and unspecified. Log hazards are calculated in 2 monthly intervals.

Table VII Orders of districts with respect to hazard and ratios of greatest to least log hazards controlled for age, sex, and specified site or not, colon cancer

\begin{tabular}{|c|c|c|}
\hline & $\begin{array}{l}\text { Low } \\
\text { hazard }\end{array}$ & $\begin{array}{l}\text { Greatest } \\
\text { least } \\
\text { hazard } \\
\text { ratio }\end{array}$ \\
\hline $\begin{array}{l}\text { Whole period } \\
\text { Months }>6 \\
\text { Months } 1-6 \\
\text { Months 2-6 } \\
\text { Month 1 } \\
\text { Days 15-30 } \\
\text { Days 0-14 }\end{array}$ & 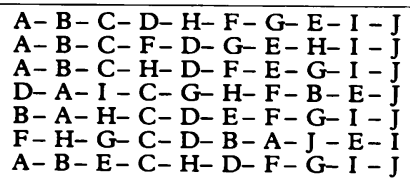 & $\begin{array}{l}1.56 \\
1.57 \\
1.52 \\
1.35 \\
1.71 \\
2.45 \\
1.97\end{array}$ \\
\hline
\end{tabular}


included the early period. The pattern of hazards observed in the first 14 days was thus important in determining the overall district order. At the extreme of short survival a sizable proportion $(8.3 \%)$ of patients with colon cancer had zero survival, that is their date of diagnosis and death on the register were the same. Variation in the rate of zero survival was not alone responsible for determining the district orders, since similar orders were found when follow up started at day one, and when the districts with highest rates of zero recorded survival were excluded. Several districts had high risk of zero survival and high hazard to early survival, but there was little correspondence between the districts with low risk and hazard respectively. So while zero survival may reflect the extreme end of low survival, it is probably, at least in part, a consequence of inadequate cancer registration.

In 1982 in a study of the effectiveness of screening for colorectal cancer, 17824 residents of Farnborough and Basingstoke were offered the haemoccult test for colorectal cancer. ${ }^{7}$ Basingstoke is district $\mathrm{A}$ in our study. A random half of the 17824 residents were sent an educational booklet about bowel cancer, though this had little effect on compliance. Of the 7545 completed tests 75 were positive, and of these 63 were investigated, 52 having neoplastic disease or non-neoplastic colorectal conditions, three had gastric conditions, and eight had no abnormality. Thus during our study period colorectal cancers were detected much earlier for some residents of one district than elsewhere. The involvement of family doctors and a large part of the community in the study, and the distribution of educational booklets is likely to have increased awareness of the disease and its symptoms, and this might be expected to have a sustained impact on stage at presentation in subsequent years. It is thus interesting to note that Basingstoke had the highest survival rates with colon cancer in our study, and also a low rate of registrations at the time of death.

In a study of survival with breast cancer Pocock et $a l^{\beta}$ compared long term survival with that expected from the age, sex, and year of onset for each patient. Examining excess mortality showed that patients were still experiencing a small degree of increased risk after 15 years. Analysis of excess over expected population mortality has been developed for use with Cancer Registry Data ${ }^{9}$ where disease specific death rates are not available, and has been used in comparing survival with colon cancer ${ }^{10}$ and with breast and prostatic cancer, ${ }^{11}$ across hospital districts in Finland using separate sets of all cause mortality rates for each district. Patients suffering from colorectal cancer tend to be in their sixties or older, and in this period mortality from other causes increases rapidly with age. Here all cause survival with colon and rectal cancer has been compared between the districts using the Cox regression model and the possibility that age/sex specific death rates from causes other than colorectal cancer differ over districts remains; however our study has focused on short term survival where deaths are more likely to be attributed to the disease. Patients notified to the registry at the time of their death may be more likely to have died from causes other than colorectal cancer, but district orders were not greatly changed when these cases were omitted from analysis.

One finding from our study was the impact on survival with colon cancer of the variable representing site of cancer specified or not Unspecified site for colon cancer was significantly associated with shorter survival time, to the extent that it was more important in explaining differences in survival than either the district variable, or site among those cases for which it was specified, and it approached the explanatory power of age. It may be that sites are unspecified because patients are not diagnosed until a late stage of the disease, rendering it difficult and pointless to identify the specific site of the original cancer. If there is this link between the stage of cancer and whether or not a site is specified, unspecified site could act as a proxy for stage in taking into account possible differences in late referral between districts. Did differences in the percentage of unspecified site codes across districts explain the district differences in survival for colon cancer? The answer is no. The districts of residence which showed higher risk when considering survival times were not similar to those which had high percentages of unspecified site codes, and the district differential in survival with colon cancer remained largely unaltered after unspecified site was controlled in the analysis. Unspecified site was included in the analysis in an attempt to control for stage. However, the range in rates of unspecified site across districts, from $25 \%$ to $60 \%$, was so large that variation in coding practice by clinicians and clerks must be an important determining factor as well as any inherent inability to establish site. If staging data had been available, it would have been possible to clarify the extent to which unspecified site indicates an advanced stage of cancer. The Wessex Cancer Intelligence Unit is at present engaged on a project in which data will be collected retrospectively in selected districts in Wessex by referring to the actual case notes. Tumour staging will be among the information gathered.

Our thanks are due to L Brewster, L Izzard, and G Ogilvie for their help in preparing the tables and plots, and to the referee for suggesting several improvements to the analysis and discussion. Part of the analysis was carried out while the second author was undertaking research leading to an MSc at Southampton University.

1 Gill PG, Morris PJ. The survival of patients with colorectal cancer treated in a regional hospital. Br f Surg 1978; 685: $17-20$.

2 Holliday HW, Hardcastle JD. Delay in diagnosis and treatment of symptomatic colorectal cancer. Lancet 1979; treatme 11 .

3 Simpson R, Bennett J. Cancer in Wessex 1975-1983. Southampton: Wessex Cancer Intelligence Unit, 1987. Southampton: Wessex Cancer Intelligence Unit, 1987.

5 Cox DR. Regression models and life tables. $f R$ Stat Soc (B) 1972; 34: 187-220.

1972; 34: 187-220.
BMDP Statistical Software Manual. California: University BMDP Statistical Software
of California Press, 1985.

7 Nichols S, Koch E, Lallemand RC, et al. Randomised trial of Nichols S, Koch E, Lallemand RC, et al. Randomised trial of
compliance with screening for colorectal cancer. $B M F$

8 Pocock SJ, Gore SM, Kerr GR. Long term survival analysis: the curability of breast cancer. Stat Med 1982; 1: 93-104. Hakulinen $T$, Tenkanen $L$. Regression analysis of relative survival rates. Appl Stat 1987; 36: 309-17.

10 Hakama M, Karjalainen S, Hakulinen T. Outcome-based equity in the treatment of colon cancer patients in Finland Int $\mathcal{F}$ Technol Assess Health Care 1989; 5: 619-30.

11 Karjalainen S. Geographical variation in cancer patient survival in Finland: chance, confounding, or effect of treatment? $f$ Epidemiol Community Health 1990; 44: 210-14. 